\title{
Docencia universitaria estomatológica en cuarentena
}

\section{Stomatological university teaching in quarantine}

El inicio de la cuarentena obligatoria debido a la pandemia del coronavirus ha significado el realizar muchos cambios en nuestro país, desde los hábitos de higiene y prevención hasta las costumbres de socialización interpersonal.

Dentro de estos cambios la docencia universitaria estomatológica es una de las áreas que ha sufrido más restricciones, especialmente porque la Carrera de Estomatología involucra un gran porcentaje de componente practico lo cual ha sido limitado por nuestro gobierno peruano. A diferencia de otras carreras universitarias cuyos componentes para el dictado de clases en aulas es mayor lo cual ha facilitado que las clases virtuales se puedan desarrollar sin ningún problema, en la carrera de estomatología, si bien es cierto, el componente teórico ha podido desarrollarse a través de clases virtuales es importante señalar las limitaciones que se han tenido para desarrollar el componente práctico. Frente a esta limitación en la Facultad de Estomatología de la Universidad Peruana Cayetano Heredia, gracias al desarrollo del sistema de historias clínicas digitales creado hace 6 años, el cual cuenta con una gran número de estas historias, lo que ha permitido que los alumnos de pregrado puedan desarrollar las capacidades de diagnóstico estomatológico, piedra angular en el proceso de una enseñanza estomatológica eficiente. Es decir que contando con ese instrumento de docencia se han podido impartir conocimientos que han servido a los alumnos para incrementar su capacidad diagnóstica. Pensamos que dos componentes desarrollados durante estos tres meses de cuarentena obligatoria, como son las clases virtuales y el proceso de enseñanza virtual de diagnóstico y plan de tratamiento estomatológico, han llegado circunstancialmente para quedarse en forma definitiva.

A nivel de posgrado la experiencia también ha sido enriquecedora porque los cursos virtuales a nivel de posgrado han impulsado la educación a distancia especialmente con la participación de colegas a nivel nacional e internacional.

En nuestra Facultad la constante ha sido el cambio, y por ello en aplicación a este principio las dos formas de enseñanza impartidas durante la cuarentena han sido experiencias muy positivas que han motivado tanto al alumnado como al cuerpo docente llegándose a tener resultados muy satisfactorios.

Hugo Ronquillo-Herrera 1,a.b,c; 2,d

Facultad de Estomatología, Universidad Peruana Cayetano Heredia. Lima, Perú.

Academia de Estomatología del Perú y la Sociedad Peruana de Prótesis Dental y Maxilo Facial.Lima, Perú

Editor Jefe de la Revista Estomatológica Herediana

Profesor Asociado

Maestro en Estomatología, Título de Especialista en Rehabilitación Oral

Miembro Vitalicio 